"This is the peer reviewed version of the following article: [Australian Journal of Public Administration, 2018, in print]. which has been published in final form at [https://onlinelibrary.wiley.com/action/doSearch?AllField=Is+a+Problem+Shared+a+Probl em+Halved\%3F+Shared+Services+and+Municipal+Efficiency]. This article may be used for non-commercial purposes in accordance with Wiley Terms and Conditions for Self-

Archiving." 


\section{Is a Problem Shared a Problem Halved? Shared Services and Municipal Efficiency}

It has long been argued that shared services represent an efficacious means of securing efficiencies for municipalities. Indeed, pressures from fiscal austerity, taxation limitations, and the spectre of forced amalgamations have resulted in an increasing uptake of shared service arrangements. However the extant evidence is rather inconclusive and is largely restricted to analysing the nett efficiency outcomes for the specific service shared. We broaden this evidential base by examining the association between shared service production and the efficiency of entire municipalities. Our analysis, employing a five year panel of data, suggests that shared services are associated with a statistically significant reduction in overall municipal efficiency. We conclude by explicating on the public policy implications arising from our prima facie surprising results.

Shared services are increasingly being seen as an efficacious means of securing efficiencies in the production of municipal goods and services. In America fiscal pressures arising from taxation limitations, in particular, combined with concerns regarding equity and difficulties prosecuting consolidations have largely been the impetus for municipalities to embark on cooperative arrangements (Feiock, 2007). In Europe, fiscal austerity has been the main motivation for municipalities entering into shared service arrangements even though there are relatively fewer barriers to consolidation (Bel and Warner, 2014). By way of contrast shared services in the Antipodes mainly arise in response to higher-tier government threats of consolidation designed to address waning financial sustainability (Dollery et al., 2016). Indeed, in response to a belief in the efficacy of shared services, some higher-tier governments have provided substantial financial and legislative support to facilitate cooperative ventures. It is therefore important that we have a comprehensive understanding of the efficiency outcomes that might be expected.

However, the extant empirical evidence on shared services is rather mixed and inconclusive (Aldag and Warner, 2017). Moreover, evidence is largely restricted to an analysis of the nett pecuniary outcomes for the specific service produced co-operatively (often solid waste disposal, and generally employing only a single year of data) or on case-studies of shared services in a single municipality (see, for example Conway et al. 2011; KPMG, 2015). We seek to broaden the evidential base by considering the effect of shared service production on the efficiency of an entire jurisdiction of municipalities over a five year panel of data. As we will explain below, there are a number of costs that are largely exogenous to the specific shared service being produced that might reasonably be expected to affect efficiency of the municipality as a whole. Analyses that do not look beyond the shared service in question might reasonably be expected to overlook these exogenous costs and thus produce a more favourable view of the efficiency implications arising from shared services than might be strictly warranted.

The main reason put forward for considering shared service provision of municipal goods and services relates to the potential for fragmented municipalities to achieve optimal output size 
for specific functions and hence capture economies of scale (Kwon and Feiock, 2010; Bel and Warner, 2014). However, there are other reasons for pursuing shared services, apart from the hope of securing efficiencies (although the promise of efficiencies are the most cited and prominent reason; Feiock, 2007). For instance, shared services are often pursued by municipalities purely as a means to escape amalgamations (the argument generally proceeds along the lines that shared services can capture efficiencies relating to scale without the loss of identity and disruption associated with amalgamation; Conway et al., 2011). In addition, shared services may be pursued in order to augment limited managerial and technical expertise (Bel and Warner, 2014; Dollery et al., 2016), reduce professional isolation (Conway et al., 2011), facilitate co-ordination of regional infrastructure planning (Kim and Warner, 2016), promote innovation (Carr and Hawkins, 2013) and improve service quality (Aldag and Warner, 2017). Moreover, shared production of municipal goods and services can provide an efficacious path to internalising externalities (whereby benefits or costs imposed on municipal neighbours as a result of municipalities operating in isolation become distributed to partner municipalities in the event that the relevant service is shared; see Kwon and Feiock, 2010). Shared services might also be pursued in order that political representatives can secure benefits (such as additional or improved services) for defined constituent groups and take credit for same, which explains why shared services are more common where mayors are directly elected (see, Dollery et al., 2016).

This paper addresses an important gap in the scholarly literature by providing a robust assessment of the association between the efficiency of an entire municipality and whether or not the municipality was involved in at least one shared service arrangement. We also investigate the association between specific categories of shared services and municipal efficiency, by employing an exhaustive eight part typology in a sequent set of analyses. To achieve our objective of understanding the effect of shared services on municipal efficiency we first construct a theoretical framework to describe the benefits and costs of shared services, drawing largely from the transaction cost theory approach which is the dominant framework in this field. Particular attention is paid to exogenous costs arising from shared services that might be otherwise overlooked by analyses restricted to only the service shared (rather than the entire municipality). Following this we outline our empirical methodology and data sources employed to investigate the two propositions developed in the earlier section. Thereafter we present the results arising from our second stage regressions of a five year panel of efficiency data (2012 to 2016 inclusive) based on the entire cohort of 68 general purpose municipalities which comprise the jurisdiction of South Australia. We conclude our paper with a discussion of the public policy implications arising from our study. 


\section{The Conditions Required for Efficient Shared Services}

Nett efficiency of shared services is equal to the difference between production benefits and the transaction and agency costs associated with managing the co-operative venture (Kwon and Feiock, 2010). Production benefits are mostly attributable to economies of scale which refer to the case whereby long-run average total costs fall as output increases. It should be noted that not all municipal services exhibit economies of scale, and even when total average costs are responsive to output size this association generally only holds over relatively short domains (Fahey et al., 2016). Once economies of scale have been fully exhausted (that is, when average total costs cease to decrease with increased output and hence efficiency is first maximised) production generally enters a relatively lengthy domain of constant returns whereby there is no change to average total costs as output increases (and there is therefore no change to efficiency for the particular service in question). If output is expanded even further, then diseconomies of scale emerge - average total costs begin to increase as output increases - and relative inefficiency sets in. Figure 1 provides a graphical depiction of the association between average total costs and output for services which exhibit scale economies. Clearly production benefits arising from shared services will be maximised where output is increased from a point to the left of the output level at which efficiency is first maximised to an output level that is less than the point at which diseconomies of scale set in. The first obstacle then in reaping nett efficiencies from entering into shared service arrangements is to select a service for which an association between average total cost and output size exists, and for which the combined production of partner municipalities will not incur significant diseconomies of scale.

\section{[Please insert Figure 1 here]}

Even if economies of scale can be captured, the existence of transaction and agency costs directly associated with the co-operative arrangement may well consume the entire efficiencies generated, or indeed exceed the benefits and therefore generate nett inefficiency (Feiock, 2007). Transaction costs arise due to uncertainty regarding future events, information asymmetry and opportunistic behaviour of others, and occur in both shared and in-house production (but are more easily managed in the latter; Brown and Potoski, 2005). Transaction costs include information and co-ordination costs, negotiation and division costs, monitoring and enforcement costs, and defection costs.

Information and co-ordination costs include the expense of garnering information on prospective partners (their preferences and resources) and ensuring that all partners are kept informed regarding the performance of the shared venture (which might involve the expense of engaging staff to administer the enterprise (Dollery et al., 2016) along with costs associated with meeting statutory and accounting standard requirements). Negotiation costs relate to the initial expense of coming to agreement regarding the quantity and quality of shared services to be produced and how the venture will be resourced. Division costs are the outcome of negotiations and refer to how the gross transaction surplus is distributed among shared service partners (see, Kwon and Feiock, 2010). There is some evidence to suggest that transaction surpluses are not always distributed evenly as a result of the bargaining process, 
and that bigger municipalities may use their relative power to obtain a disproportionate share of the gross savings arising from the venture (Carr and Hawkins, 2013). Moreover, the heterogeneity of different partners often means that relative division surpluses might differ substantially even if the gross transaction surplus is distributed evenly. This is because different partner municipalities are likely to have provided different standards of services and have had different unit costs for producing the service.

The performance of the shared service venture and the partners themselves must be monitored to ensure that commitments are kept and opportunistic behaviour does not occur. Moreover, if unsatisfactory behaviour is identified then enforcement costs are likely to be borne by the party seeking to correct unsatisfactory behaviour. Defection costs are the last component of transaction costs and are generally considered to refer to the cost incurred when a partner municipality to a shared service withdraws from the co-operative venture (Conway et al. 2011; Dollery et al. 2016; Carr and Hawkins, 2013). This cost occurs due to the change in service level output (reduced output may result in an increase to the long-run average total cost), potential need to renegotiate contracts, potential need to purchase new plant and equipment, and the loss of institutional learning or expertise (especially if the withdrawing municipal had contributed staff which they withdraw) that may accompany defection. There is also a contingent cost, that is often overlooked in the literature, associated with the mere threat of defection. If other members of a co-operative venture suspect that one of the partners is disenchanted with the arrangements, and may therefore defect, then they may be more likely to bow to the potential defectors preferences (for instance, altering service levels) or even re-distribute the bargaining surplus. As a result the mere threat of defection might result in higher transaction costs.

Agency costs are 'a cousin of transaction costs', and refer to expense associated with information asymmetry and goal incongruence (Brown and Potoski, 2003, p. 446). In this regard, it is important to note that there are two levels of agency in operation with respect to shared services. First, municipal executives and elected representatives act as agents of municipal taxpayers. Second, representatives on the shared services board or committee act as agents for their municipalities. At each level of agency hierarchy it is possible that the agents will not faithfully represent the wishes of their principals (either as a result of incomplete knowledge of wishes, as a consequence of the heterogeneity of wishes, or due to disregard of the principal's wishes).

Failure to accurately represent the wishes of principals at either level will erode the efficiency dividend that lies at the core of the Decentralisation Theorem (the theorem provides an efficiency rationale for provision of goods and services through municipal government; Oates, 1999). That is, decentralised government is more efficient largely as a result of services being tailored to the different tastes of municipal residents and taxpayers. If these different tastes are not communicated clearly and not reflected in the service levels actually provided by the cooperative venture, then the very source of efficiencies for decentralised government will be largely negated. An additional agency cost occurs when the agent is not wholly committed to the idea of shared services (perhaps the agent was compelled by their municipality to participate or perhaps the agent has changed due to sequent elections or staff 
movements) and this may give rise to the convoy problem (whereby the shared service venture is hampered by the level of engagement of the least committed agent; see Dollery et al. 2016).

Figure 2 provides a summary of the nett efficiencies arising from shared services when analysis is restricted to the service itself, rather than the entire municipality ( $\beta$ is included as a weighting proportional to both the number and heterogeneity of shared service partners to respond to the literature that indicates that nett efficiency is likely to be eroded by multiple heterogeneous partners).

[Please insert Figure 2 here]

However, we believe that there are a number of exogenous costs that might be overlooked by analyses that do not examine nett efficiency at the level of the entire municipality. For instance, producing a service co-operatively may result in an erosion of extant economies of scope for the municipality. Economies of scope refer to the savings that may be realised when a single organisation uses the same factor inputs to produce two or more services. If a service is moved from a municipality to a shared service venture, extant economies of scope may be diminished thus reducing efficiency when considered at the level of the entire municipality. In similar vein, if staff and resources previously dedicated to produce a service that is moved to a co-operative venture, are not transferred to the venture, meaningfully redeployed, dismissed or sold, then this also will have a deleterious effect on municipal efficiency. It is also possible that internal division between and within staff and elected representatives might result in further efficiency reductions that will be felt at the municipal level. Time taken to resolve differences between staff and representatives has a direct effect on efficiency, but there is also an indirect effect that arises from the diversion of organisational attention. Indeed, it is quite possible that there will be differences between and within staff and elected representative cohorts given that shared services has implications for the level of staffing, opportunities for staff advancement, control over service levels and ideology.

Another exogenous cost relates to residual costs associated with the service that are retained by the municipality that might escape notice in a service level analysis. In particular, complaints and inquiries are still likely to be directed to the municipality even after the service has been shifted to a co-operative venture (thus continuing to consume municipal resources). A final potential exogenous cost is the loss of skills that may generate further contingency costs and constrain future options for the municipality (Feiock, 2007).

When we also consider exogenous costs, which might otherwise be overlooked by analyses that are restricted to a particular service, nett efficiencies for the entire municipality can be depicted as follows:

[Please insert Figure 3 here]

As represented in Figure 3 the difficulties in selecting a service amenable to production efficiencies in conjunction with significant transaction costs, agency costs and exogenous 
costs suggests the following proposition, which is the principal objective of our sequent empirical inquiry

Proposition 1: One might reasonably expect there to be a negative association between efficiency of an entire municipality and whether or not the municipality was involved in at least one shared service arrangement

The scholarly literature suggests that different types of services are likely to yield different efficiency outcomes (see, for example Brown and Potoski, 2005; Feiock, 2007). For instance, services that are amenable to measurement may make it less costly for municipalities to measure the performance of the co-operative venture (Brown and Potoski, 2003). However, services that require single-purpose specific assets and skills (which are difficult to redeploy) may increase the relative costs of establishing and operating a shared service (Brown and Potoski, 2005). In similar vein, heterogeneity of resident preferences between and within municipalities entering into co-operative ventures may also increase the costs, and hence reduce the efficiency, of shared services (Feiock 2007; Carr and Hawkins, 2013). To investigate the question of service specific effects in a little more detail we developed a second, subordinate proposition:

Proposition 2: One might reasonably expect different types of shared services to exert different effects on municipal efficiency in response to variation in barriers to measurability, degree of specificity, or heterogeneity of resident preferences.

We now outline the two part empirical methodology that we employed to investigate the two propositions. 


\section{Empirical Methodology}

To investigate the propositions developed earlier we conducted two-stage empirical analyses of relative technical efficiency for the 68 general purpose municipalities that constitute the jurisdiction of South Australia over five financial years (2012 to 2016 inclusive). It might be noted that municipal government in Australia has a relatively limited remit, compared to jurisdictions abroad, that is focussed on the provision of road infrastructure and services to properties (such as waste removal; see Grant and Drew, 2016 for a thorough account of Australian Local Government). Most services to people - police, health, education and welfare - are provided by state and federal government in Australia. In the first stage of our analysis we estimated the relative technical efficiency of each municipality for each year by employing data envelopment analysis (DEA). In the second stage we regressed the relative technical efficiency scores against control variables and indicators responding to whether or not the municipality was involved with shared services.

\section{Data Envelopment Analysis}

DEA measures the relative efficiency of the conversion of inputs into a specified set of outputs. DEA was selected to measure relative technical efficiency as it does not require $a$ priori specification of functional form (which is often problematic to justify), and allows for the inclusion of multiple disaggregated outputs which, whilst not a perfect reflection of efficiency, is an improvement on other methodologies (such as unit cost analysis or stochastic frontier analysis (SFA); Drew et al. 2015). In the calculation of efficiency, an inputorientation was selected as the output of municipalities are generally considered to be fairly exogenous (Worthington and Dollery, 2001). DEA employs linear programming to first establish an efficient frontier that represents municipalities which best minimise inputs for the level of output produced - these municipalities are assigned a relative technical efficiency score of 1.0. The input/output conversion of the remaining municipalities are then compared to the frontier and municipalities lying in the interior of the curve are assigned scores less than 1 , based on their radial distance from comparable peers. Super efficiency scores were assigned to municipalities that had input/output conversion ratios exceeding their peers on the frontier and these municipalities were identified by imposing a constraint on the linear programme that prevented a municipality from using itself as a peer (Coelli et al. 2005).

Figure 4 provides a graphical depiction of DEA - in this diagram municipality A would be assigned a score of 1.0 (as it lies on the frontier), municipality B would be assigned a score less than one (because it lies on the interior of the frontier) and municipality $\mathrm{C}$ would be super-efficient (and hence be assigned a score greater than 1.0). To eliminate potential bias in the second stage regressions (which we detail in the next sub-section) a constant returns to scale (CRS) model was employed. It is important to note that no infeasible solutions were obtained upon utilisation of this method, and that all weightings obtained were non-zero. Moreover, to provide additional assurance regarding the validity of the results obtained, a supplementary model incorporating bootstrapped ${ }^{1}$ efficiency scores was also estimated. Summary statistics for the efficiency scores obtained using both the super and bootstrapped methods have been presented in Table 1. Readers requiring a more detailed explanation of 
this increasingly common empirical technique are referred to the seminal work of Cooper et al. (2007).

[Please insert Figure 4 here]

Just like all empirical estimations our DEA employs proxies to measure output. Use of proxies is dictated by data availability and constraints on the number of outputs that can be accommodated by the technique (Nunamaker's (1985) rule restricts the total number of inputs and outputs - see also Cooper et al. 2007). We employed a total of five output proxies that respond closely to the remit of Australian municipalities - where the single largest cost is the provision of road infrastructure (approximately one-fifth of total municipal expenditure (SALGGC, 2015)) followed by services directed to properties (Grant and Drew, 2017). Proxies, of course, are not perfect representations of output, but we do note that our use of DEA has allowed us to include five times as many outputs as other techniques for estimating efficiency (for example, SFA) and that we also capture differences in quantity and quality of outputs through our controls employed in the second stage regressions (see below). The inputs to our DEA were staff and operational expenditure (which are pretty standard inputs for most DEAs), and our outputs were sealed roads, unsealed roads (generally graded dirt), number of business assessments, number or residential assessments, and other (principally farm and vacant lots) assessments (see Table 1). It is important to disaggregate the various types of roads and assessments to capture the different costs and services associated with them (for instance, farm properties do not receive rubbish collection, and unsealed roads generally require more frequent, but less expensive, maintenance). Our DEA specification is consistent with a host of studies performed in the Antipodes and readers can consult Drew et al. 2015 for an in-depth analysis that confirms our proxy selections as the most appropriate case. However, due to the fact that this technique, nor any other technique, can incorporate a complete rendering of every municipal output (were the data even available) readers should remain cognisant of this potential limitation when considering the evidence (in the same manner that readers should be aware of the limitation involving the necessary use of proxies in most empirical work within the corpus of scholarly literature).

[Please insert Table 1 here]

\section{Second-Stage Regression}

Second-stage regressions were conducted to determine whether there were statistically significant associations between municipal efficiency estimates and the use of shared services. About a third of municipalities operated at least one shared service during the five financial years of analysis. In total we conducted four regressions - the first two regressions (Models 1 and 2) measured the association between municipal efficiency and the use of at least one shared service arrangement (later disaggregated into eight categories). Thus Models 1 and 2 respond to the first proposition developed earlier. The next two models ( 3 and 4) replace the single dummy variable for shared services with eight dummy variables, representing the different categories to which all shared service arrangements observed could be classified to, in order to shed some light on our second proposition. 
Although the efficiency scores obtained under a super-efficiency approach are not bounded by an upper limit (evident through the fact that the scores obtained can exceed a value of 1), they still contain a lower bound (as the efficiency scores cannot be negative). Furthermore, for the supplementary model (Model 4) employing bootstrapped efficiency scores, both an upper and lower limit exist (as the efficiency score obtained must lie between 0 and 1). Consequently, to account for the censoring inherent in the efficiency scores obtained, a tobit model is generally employed. Due to an unfavourable Hausman test result, indicating the presence of endogenity, random effects tobit was not used. We therefore conducted a time fixed effects tobit (to account for the individual level differences in a fixed slope, rather than error term $)^{2}$. The model employed can be expressed as:

$\boldsymbol{E}_{i t}=\alpha_{i t}+\beta_{1} \boldsymbol{X}_{i t}+\beta_{2} \boldsymbol{S}_{i t}+\mu_{i t} \quad i=1 \ldots 68 t=1 \ldots 5$

Where $\mathbf{E}$ is the super efficiency score (and bootstrapped efficiency in Model 4), $\mathbf{S}$ is a binary variable coded 1 if the municipality operates under at least one shared service arrangement (note that this coding system was also applied in models that subsequently disaggregated shared services into eight individual categories), and 0 otherwise (if they do not have a shared service arrangement), $\mathbf{X}$ is a vector of control variables which are expected to influence municipal efficiency (the full list is provided below and in Table 1), and $\mu$ is an independent and identically distributed error term. For the second stage regression - employed to answer our research question regarding the efficiency effects of shared services - the controls selected included the population size (as a proxy for municipal size), population density, the demographics of the residents served (measured through the proportion of residents under the age of 15 , the proportion receiving the aged pension, and the proportion of individuals from an Aboriginal or Torres Strait Islander background, or from a non-English speaking background), the socio-economic status of residents (through the median wage received, and the proportion of unemployed residents receiving a Newstart allowance) and the federal assistance grant revenue received by a municipality. The authors experimented with different specifications and found no material difference for the variable of interest (shared services). In particular, the inclusion of grants did not affect the statistical significance or sign of the shared services dummy, nor did the use of variable returns to scale efficiency scores (or bootstrapped scores).

The population variables were selected to account for the potential presence of economies (and diseconomies) of scale in municipal service provision (see Kwon and Feiock, 2010), which can serve to increase (or decrease) the efficiency of an individual municipality (note to achieve this, and account for the non-linear relationship between costs and output, a quadratic term was included for Models 2, 3, and 4). Similarly to account for potential economies of density (whereby the average cost decreases as population density increases; Holcombe and Williams, 2008)) the variable of population density was included. Measures of population demographics and socio-economic status were included due to strong evidence in existing literature on the effect which deprivation has in influencing the demands of residents for quantity and quality of services, and hence relative technical efficiency estimates (see 
Andrews, 2004). In an analogous reasoning, the urbanity of the municipality was controlled for in response to the well-documented evidence of different service levels and unit costs which are incurred in rural and urban areas respectively ${ }^{3}$ - specifically, persons in rural areas generally receive less services (for instance waste collection may not be available) and lower quality services (culverts rather than drain infrastructure; see Grant and Drew, 2017). Finally the inclusion of data relating to federal assistance grants is justified due to the previously observed impacts on raising municipal spending (known as the flypaper effect), potentially serving to lower municipal efficiency (Dollery and Worthington, 1995). Variables have been transformed into logarithms where necessary to account for skewed distributions. Summary measures for the variables employed in this analysis are presented in Table 1.

Data for the analysis was sourced from the respective audited financial statements obtained from municipalities, the Australian Bureau of Statistics (ABS) National Regional Profile (ABS, 2017), and the South Australian Local Government Grants Commission Annual Reports (see, for example, SALGGC, 2015) ${ }^{4}$ The various reports were combined to provide full and consistent strongly-balanced panels of data (that is, the ABS (2017) report goes back to 2012 and this data was augmented with the relevant data from other sources to produce a single consistent database for analysis). The data relating to the shared service arrangements undertaken by municipalities was obtained from the Note 19 (although this number may occasionally vary) of the Notes to and Forming Part of the Financial Statements examining Joint Ventures and Interests in Other Entities, supplemented by the appendices to the annual reports relating to annual reports of regional entities and subsidiaries. If a municipality did not operate under shared service arrangements, this information will not be present in the annual report (although memberships of municipal associations may be provided). 


\section{Associations Between Relative Technical Efficiency and Shared Services}

To investigate the two propositions developed from theory we ran a total of four second-stage regressions. The first two models were directed at determining whether a statistically significant association existed between the provision of at least one shared service and relative technical efficiency (TE), with appropriate controls. The third model examined the association between the eight different types of shared services provided by the 68 South Australian municipalities (over the period 2012 to 2016 inclusive) and relative TE and was designed to cast further light on Proposition 2. This analysis was then repeated in Model 4, in order to provided additional assurance regarding our results (we also re-ran the regressions using OLS and found no real difference in the regressors of interest). Our results are summarised in Table 3.

\section{[PLEASE INSERT TABLE 3 HERE]}

In Model 1 we ran our second-stage regression with a linear term to measure the effect of population size, and employed a single dummy variable to control for whether or not the municipality participated in at least one formal shared service arrangements. All of the regressors had signs consistent with what we might expect given the extant literature: That is, efficiency was positively associated with population density (economies of density, where a $1 \%$ increase in density was associated with an increase in relative TE of 0.0006), distribution of age cohorts (a one unit increase in the proportion of residents under 15 was associated with an increase in relative TE of 0.025 and a $1 \%$ increase in persons receiving an aged pension was associated with an increase in relative TE of 0.0028), and proportion of persons speaking a language other than English at home (where a 1\% increase in the proportion of NESB persons was associated with an increase in relative TE of 0.0004). Moreover, statistically significant negative associations were found for median wage (an increase of $\$ 1,000$ in the median income was associated with a decrease of relative TE in the order of 0.008), proportion of indigenous persons (a 1\% increase was associated with a 0.00067 decrease of relative TE), proportion of persons receiving Newstart welfare benefits (a $1 \%$ increase in the proportion of Newstart recipients was associated with a 0.0018 decrease in relative TE) and population size (a 1\% increase in population was associated with a decrease in relative TE of 0.0018). Rural municipalities were more efficient than urban municipalities (which are the reference category), ceteris paribus. In general the control variables only had relatively small associations with relative TE (given that super-efficiency scores were distributed at an average of 0.876) but their statistical significance confirms their importance to a robust analysis of the association between shared services and relative TE.

Notably the dummy variable for shared services in Model 1 was statistically significant at the $5 \%$ level and suggests that, holding all other factors constant, municipalities that participate in at least one shared service might be expected to have lower efficiency in the order of 0.0677 (recall that the super-efficiency score did not require transformation and the response might be interpreted in terms of the average of the distribution which was 0.876). It thus seems as if there is strong support for our first proposition. 
However, there is a good deal of literature to suggest that $\mathrm{u}$-shaped production functions might be more appropriate for second stage regression analyses (we note that under the constant returns to scale efficiency specification there is no size constraint regarding which peers municipalities are benchmarked to and hence a quadratic specification is more plausible). When we added the higher order population term (Model 2) we found that most regressors attenuated slightly. Moreover the population coefficients suggest a local minima at around 75,183 - that is, efficiency is expected to reduce for populations up to this point, then recover (at least in part) for larger population sizes.

In Model 2 our main regressor of interest was statistically significant at the $1 \%$ level, and suggested slightly higher reductions in relative TE in the order of 0.0847 , ceteris paribus. That is, our more comprehensive analysis of the association between municipal efficiency and the provision of at least one shared service suggests that participation in co-operative ventures might be expected to result in considerably lower relative TE (which we have now demonstrated at the highest level of statistical significance). Given the distribution of relative TE (mean 0.876), this is quite a strong association. Thus Model 2 confirms the strong evidence to support Proposition 1 which we developed earlier.

Proposition 2 suggests that different shared services might be associated with different effects on municipal efficiency in response to variations in measurability, specificity and heterogeneity of resident preferences. To investigate this proposition further, in Model 3 we replaced our single shared service dummy variable with the exhaustive list of eight different shared service types (that is, all shared services in operation in South Australian municipal government over the period of analysis were assigned to one of eight categories) and found that three of the shared services had statistically significant coefficients. Specifically, shared services for waste collection, flood mitigation works, and procurement had statistically significant and relatively responsive coefficients (reductions in efficiency in the order of $0.0816,0.0925$, and 0.1197 respectively), ceteris paribus. These results serve to confirm that different types of shared service arrangements might be expected to exert different effects on municipal efficiency. Moreover, there were a few positive associations (shared health and shared equipment) that, whilst not statistically significant, do hint at the possibility that some types of arrangements might have beneficial effects on municipal efficiency. Unfortunately there was no obvious pattern between the magnitude of associations and the characteristics of the three services (see Table 4). Thus whilst we have been able to show that the efficiency outcomes associated with different shared services do vary, we haven't been able to cast much light on the importance of measurability, specificity and homogeneity which have been proposed in the literature to be predictors of success in shared service arrangements (see, Brown and Potoski, 2005; Carr and Hawkins, 2013; Feiock, 2007), and this is therefore an important area for future scholarly work.

[Please insert Table 4 here] 


\section{Public Policy Implications and Conclusion}

Despite being oft lauded as a panacea for waning municipal efficiency our evidence suggests that shared services may very well result in reduced municipal efficiency. However, there still remain a number of good reasons to contemplate shared services including inter alia potential improvement to service levels, access to expertise that might otherwise be difficult to attract, more effective regional planning, and internalisation of externalities. We simply draw attention to the fact that the first proposition derived from theory and our robust empirical evidence runs counter to many service specific assertions and that, as a result, it can no longer be considered reasonable to pursue shared services on the assumption of enhanced efficiency.

However, the evidence that we tender should not be interpreted to suggest that there is no possibility of shared services enhancing municipal efficiency. As we noted in the formulation of our propositions selecting shared services that are amendable to economies of scale, ensuring that the total output of partners does not incur diseconomies of scale, prioritising arrangements that select a small group of largely homogenous partners, minimising transaction and agency costs, and paying close attention to exogenous costs (being prepared to make the hard decisions regarding rationalisation of staff and assets) might all be expected to increase the likelihood of nett increases to municipal efficiency. Furthermore, our analysis of disaggregated shared services suggests that different types of services may exert different effects on municipal efficiency. However, future scholarly work is required to provide more definitive guidance to practitioners regarding the results from our secondary proposition.

The literature has considered a number of contractual and institutional remedies that might be used to limit transaction costs, in particular (and hence maximise efficiency outcomes arising from co-operative arrangements), and these also deserve careful consideration by parties contemplating shared services. Three of the most prominent solutions are: (i) use of binding contracts or statutes (to prevent defection costs and aide enforcement of obligations; see, Dollery et al. 2016), (ii) use of adaptive agreements such as memoranda of understanding (that minimise upfront negotiation costs and allow parties the flexibility to respond to unpredictable events and opportunities sequent to the commencement of shared service arrangements; Carr and Hawkins, 2013), and (iii) mediated arrangements (whereby higher tiers of government, regulators or peak bodies offer to provide independent facilitation and hence reduce information and bargaining costs, disproportionate division costs and perhaps defection costs; see, Kwon and Feiock, 2010). Because the institutional remedies target specific costs associated with shared services it will be important for future research to try to tease out what kinds of transaction and agency costs have the greatest impact on municipal efficiency. This will be a difficult task to complete given the problems in quantifying some costs and obtaining sufficiently detailed data.

Future research might also examine the dynamics of shared service effects on municipal efficiency. The extant theory suggests that some upfront costs might be recouped over time so a study employing variables to measure the length of time for which a service had operated would provide additional important guidance to practitioners (Feiock, 2007). Similarly there 
are good reasons to suppose that multiple experiences with shared services might result in better contract management that could help to optimise municipal efficiency outcomes (Brown and Potoski, 2005). Therefore, further guidance might be forthcoming for practitioners from a future study that examined the nett efficiency outcomes from multiple shared service arrangements. In addition, a study that compares specific service level perceptions of savings with actual service level and municipality savings would (in combination with in-depth interviews) go some way towards explaining the reasons for apparent discordance between perceptions on shared services and actual outcomes.

In conclusion, this study set out to address an important gap in the scholarly literature namely to broaden the evidential base to include analysis of efficiency outcomes arising from shared services at the level of the entire municipality, to augment the extant service level studies. Our analysis of an entire jurisdiction over a five year panel of data provides evidence that shared services may indeed reduce overall municipal efficiency, which is probably contrary to most people's assumptions. This much needed contribution to the scholarly evidence base should give many stakeholders cause to pause and reconsider the efficacy of shared service arrangements for municipal government. For instance, scholars now have a research agenda (including a number of recommendations for additional required work) upon which to focus future efforts. Municipal executives and decision makers can now no longer reasonably assume that shared service arrangements will necessarily bring about desired increases to efficiency. Moreover, by making reference to the theoretical framework we developed earlier municipal executives and decision makers have been presented with a useful tool for identifying the determinants of efficiency maximising shared service arrangements. In addition, regulatory authorities now have good reason to consider more carefully the design and support for shared service arrangements that might be considered in their particular jurisdiction.

We emphasise again that this evidence should not be construed as suggesting that shared services can't improve efficiency - rather the take-home message of this paper is that arrangements must be very carefully designed if improvements in efficiency are the objective of co-operative ventures. Indeed, when it comes to co-operative ventures, our empirical evidence would seem to suggest that without very careful planning and execution that a problem shared may very well end up as a problem exacerbated. 


\section{Endnotes}

1. Bootstrapping is a re-sampling procedure that is designed principally to address sampling error (which is not strictly relevant here given that we had a census of municipalities) but has become rather de rigueur in DEA estimations.

2. The variable of interest was close to time-invariant thus fixed-effects panel regressions were not indicated

3. Note that the urban council category is used as the reference category

4. Note that the 2016 grant data is an estimate contained within the SALGGC report.

5. Note that the shared service categories presented above may be comprised of several homogeneous sub-categories (for instance health shared services incorporates the sharing of health inspection, immunisation, provision of healthcare-related information) which cannot be separately tested due to insufficient sample sizes. Also note that this is an exhaustive list of the shared service arrangements undertaken by councils in South Australia). 


\section{References}

Aldag, A, and Warner, M. (2017). Cooperation, Not Cost Savings: Explaining the Duration of Shared Service Agreements. Local Government Studies, doi: 10.1080/03003930.2017.1411810.

Andrews, R. (2004). Analysing Deprivation and Local Authority Performance: The Implications for CPA. Public Money \& Management, 24(1): 19-26.

Australian Bureau of Statistics (ABS). (2017) National Regional Profile (2011-2016) (Canberra: ABS).

Bel, G., and Warner, M. (2014). Inter-Municipal Cooperation and Costs: Expectations and Evidence. Public Administration, 93(1): 52-67.

Brown, T. and Potoski, M. (2003). Transaction Costs and Institutional Explanations for Government Service Production Decisions. Journal of Public Administration Research and Theory, 13(4): 441-468.

Brown, T. and Potoski, M. (2005). Transaction Costs and Contracting: The Practitioner Perspective. Public Performance \& Management Review, 28(3): 326-351.

Carr, J. and Hawkins, C. (2013). The Costs of Cooperation: What the Research Tells Us About Managing the Risks of Service Collaborations in the U.S. State and Government Review, 45(4): 224-239.

Coelli, T., Rao, D., O'Donnell, C., and Battse, G. (2005). An Introduction to Efficiency and Productivity Analysis. Springer: Singapore.

Conway, M., Dollery, B. and Grant, B. (2011). Shared Service Models in Australian Local Government: The Fragmentation of the New England Strategic Alliance 5 Years On. Australian Geographer, 42(2): 207-223.

Cooper, W., Seiford, L., and Tone, K. (2007). Data Envelopment Analysis. Springer: Singapore.

Dollery, B., Kortt, M. and Drew, J. (2016). Fostering Shared Services in Local Government: A Common Service Model. Australasian Journal of Regional Science, In Print.

Dollery, B., and Worthington, A. (1995). Federal Expenditure and Fiscal Illusion: A Test of the Flypaper Hypothesis in Australia. Publius 25 (1): 23-34

Drew, J., Kortt, M. and Dollery, B. (2015). No Aladdin's Cave in New South Wales? Local Government Amalgamation, Scale Economies and Data Envelopment Specification. Administration \& Society, DOI: 10.1177/0095399715581045.

Fahey, G., Drew, J. and Dollery, B. (2016). Merger Myths: A Functional Analysis of Economies of Scale in New South Wales Municipalities. Public Finance and Management, In Print (3/9/16). 
Feiock, R. (2007). Rational Choice and Regional Governance. Journal of Urban Affairs, 29(1): 47-63.

Grant, B. and Drew, J. (2017). Local Government in Australia: History, Theory and Public Policy. Springer Palgrave, Singapore.

Holcombe, R., and Williams, D. (2008). The Impact of Population Density on Municipal Government Expenditures. Public Finance Review, 36(3): 359-373.

Kim, Y. and Warner, M. (2016). Pragmatic Municipalism: Local Government Service Delivery After the Great Recession. Public Administration, 94(3): 789-805.

Kwon, S. and Feiock, R. (2010). Overcoming Barriers to Cooperation: Intergovernmental Service Agreements. Public Administration Review, November December 2010: 876-884.

KPMG (2015). Shared Service Analysis: Final report 27 May 2015. KPMG: Sydney.

Nunamaker, T. (1985). Using Data Envelopment Analysis to Measure the Efficiency of Nonprofit Organisations: A Critical Evaluation. Managerial and Decision Economics, 6(1): 5058

Oates, W. (2011). Fiscal Federalism. Edward Elgar: Cheltenham.

South Australian Local Government Grants Commission (SALGGC). (2015). Annual Report 2014-15. Government of South Australia: Adelaide

Worthington, A. and Dollery, B. (2001). Measuring Efficiency in Local Governments: An Analysis of New South Wales Municipalities' Domestic Waste Management Function. Policy Studies Journal, 29(2): 232-49. 
Figure 1. Potential Production (Scale) Efficiencies Arising From Shared Services

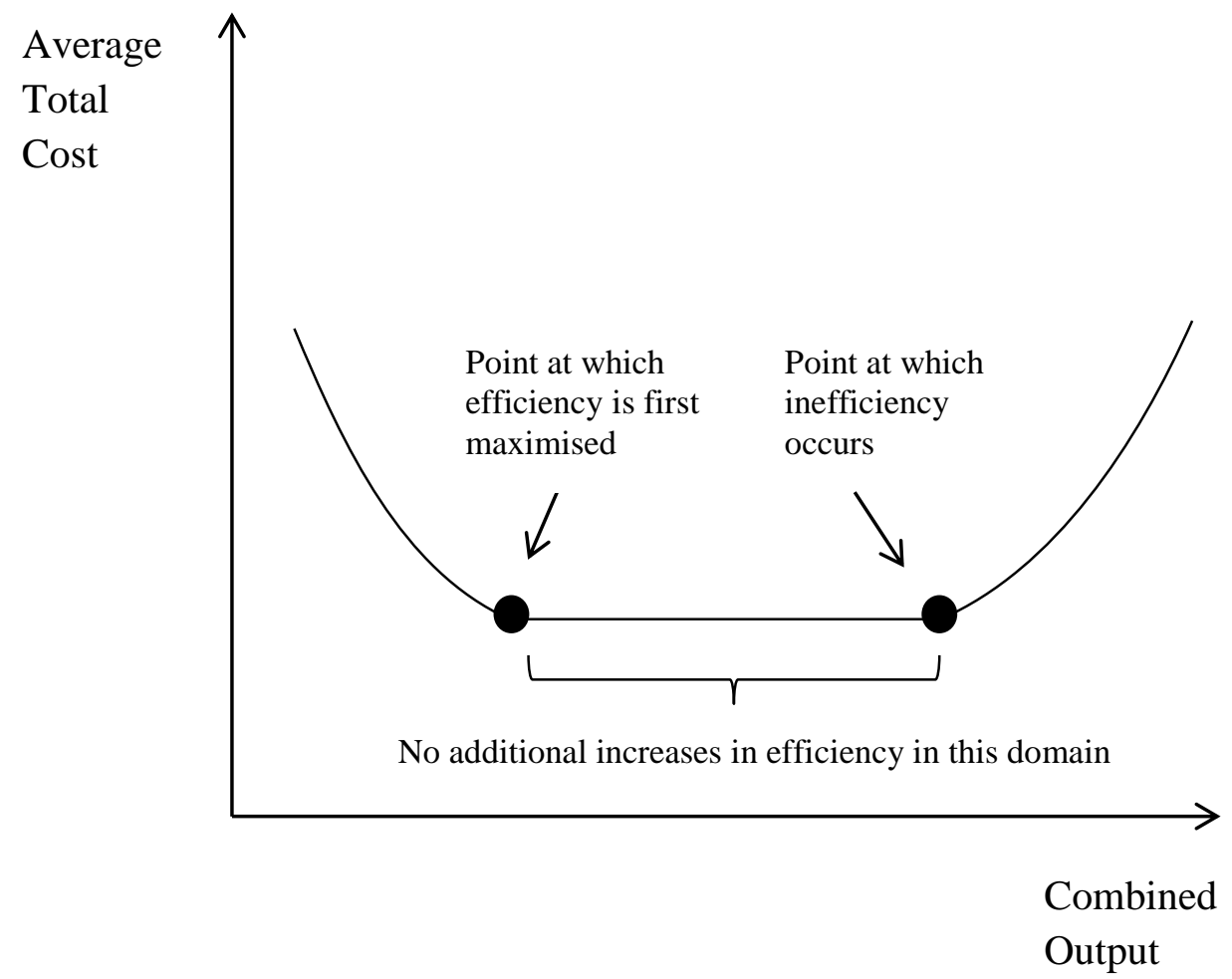

Figure 2. Nett Service Efficiency Arising From Shared Services

$\begin{gathered}\text { Service Nett } \\ \text { Efficiency }\end{gathered}=\beta\left(\begin{array}{ll}\text { Productive } & \begin{array}{l}\text { Additional } \\ \text { efficiency } \\ \text { gains } \\ \text { attributable } \\ \text { to sharing } \\ \text { of service }\end{array} \\ \text { Agency costs } \\ \text { attributable } \\ \text { directly to } \\ \text { shared service }\end{array}\right)$


Figure 3. Nett Municipal Efficiency Arising From Shared Services

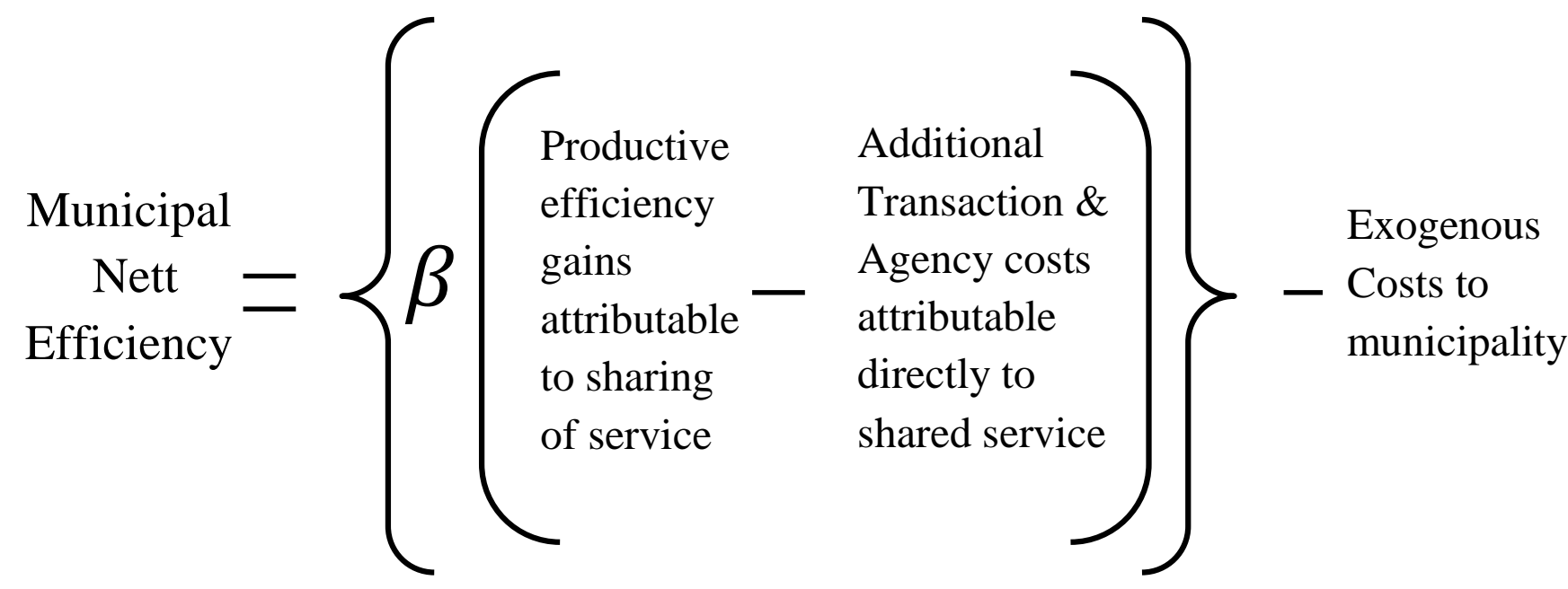

Figure 4. Input-Orientated DEA Model

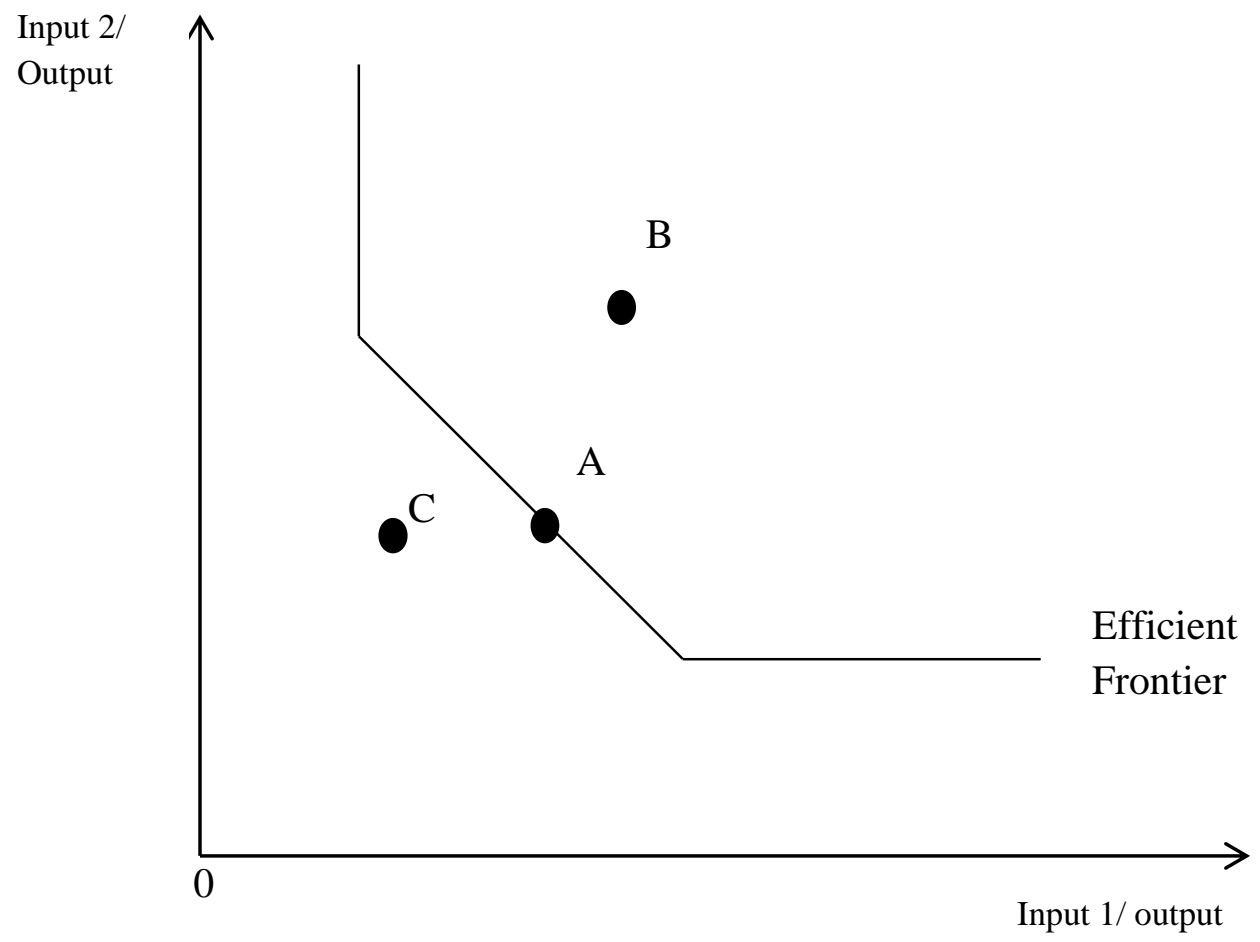

Table 1. Variables Employed in Data Envelopment and Second-Stage Regression Analyses 


\begin{tabular}{|c|c|c|c|}
\hline Variable & Definition & Mean & $\begin{array}{l}\text { Standard } \\
\text { Deviation }\end{array}$ \\
\hline \multicolumn{4}{|l|}{ Data Envelopment Analysis } \\
\hline Staff Expenses & Annual staff costs (in $\$ 000$ ) & $10,201.41$ & $12,493.56$ \\
\hline Operational Expenses & $\begin{array}{l}\text { Total expenditure less staff costs, } \\
\text { depreciation and borrowing costs } \\
\text { (in } \$ 000 \text { ) }\end{array}$ & $11,837.16$ & $13,679.19$ \\
\hline Sealed Roads & $\begin{array}{l}\text { Length of sealed (bitumen) roads } \\
\text { (in kilometres) }\end{array}$ & 267.689 & 225.271 \\
\hline Unsealed Roads & $\begin{array}{l}\text { Length of unsealed (graded dirt) } \\
\text { roads (in kilometres) }\end{array}$ & 833.656 & 839.280 \\
\hline Business Assessments & $\begin{array}{l}\text { Number of businesses with a } \\
\text { municipal area }\end{array}$ & 732.465 & 878.077 \\
\hline Residential Assessments & $\begin{array}{l}\text { Number of rateable residential } \\
\text { properties within a municipal area }\end{array}$ & $10,036.02$ & $14,053.46$ \\
\hline Other Assessments & $\begin{array}{l}\text { Total assessments less residential } \\
\text { and business assessments. } \\
\text { Generally farming and vacant } \\
\text { properties }\end{array}$ & $2,231.253$ & $1,509.801$ \\
\hline \multicolumn{4}{|l|}{ Second-Stage Regression } \\
\hline Super Efficiency & $\begin{array}{l}\text { Constant returns to scale super- } \\
\text { efficiency score for each year }\end{array}$ & 0.876 & 0.270 \\
\hline Bootstrapped Efficiency & $\begin{array}{l}\text { Constant returns to scale } \\
\text { bootstrapped score for each year }\end{array}$ & 0.826 & 0.176 \\
\hline Population (ln) & $\begin{array}{l}\text { Population size for each municipal } \\
\text { area }\end{array}$ & 9.219 & 1.389 \\
\hline Population squared (In) & Population size term squared & 86.919 & 25.872 \\
\hline Population density (In) & $\begin{array}{l}\text { Population size divided by the area } \\
\text { of the municipal }\end{array}$ & -1.893 & 3.188 \\
\hline Under 15 & $\begin{array}{l}\text { Proportion of persons under } 15 \\
\text { years of age }\end{array}$ & 17.863 & 2.867 \\
\hline Aged (ln) & $\begin{array}{l}\text { Proportion of persons on an aged } \\
\text { pension }\end{array}$ & 7.134 & 1.383 \\
\hline
\end{tabular}




\begin{tabular}{|c|c|c|c|}
\hline Newstart (ln) & $\begin{array}{l}\text { Proportion of persons receiving } \\
\text { Newstart (unemployment) } \\
\text { allowance }\end{array}$ & 5.698 & 1.479 \\
\hline NESB (ln) & $\begin{array}{l}\text { Proportion of persons speaking a } \\
\text { language other than English at } \\
\text { home }\end{array}$ & 1.489 & 1.057 \\
\hline ATSI (ln) & Proportion of indigenous persons & 0.468 & 0.881 \\
\hline Median Wage (\$’000) & $\begin{array}{l}\text { Median wage of wage earners in } \\
\text { the municipal area }\end{array}$ & 38.867 & 8.292 \\
\hline Grants & $\begin{array}{l}\text { Financial assistance grant per } \\
\text { person }\end{array}$ & 343.533 & 409.507 \\
\hline Shared Services & $\begin{array}{l}\text { Average number of shared services } \\
\text { per municipality }\end{array}$ & 0.75 & 0.89 \\
\hline
\end{tabular}

Table 2. Shared Service Classifications ${ }^{5}$.

\begin{tabular}{lll}
\hline Shared Service Type & Definition & Example \\
\hline Waste & Collection of solid waste & Rubbish bin collections \\
Water & Water provision and/or stormwater & Delivering drinking water \\
management & to households \\
Health & Community health protection & Restaurant health \\
& & inspections \\
Flood & Floodplain management and & Levee repair, river debris \\
& infrastructure maintenance & removal \\
Transport & Community transport services & Community buses \\
Cemetery & Operation of cemeteries & Digging and maintaining \\
& & burial plots \\
Equipment & Joint ownership of equipment required & Sharing of road \\
& to perform municipal functions & maintenance machinery \\
Procurement & Sourcing of goods, partners and & Negotiation of service \\
& suppliers & contracts \\
\hline
\end{tabular}


Table 3. Second Stage Regressions of South Australian Municipal Efficiency, 2012-2016.

\begin{tabular}{|c|c|c|c|c|}
\hline & $\begin{array}{l}\text { Model } 1 \text { Super } \\
\text { Efficiency }\end{array}$ & $\begin{array}{l}\text { Model } 2 \text { Super } \\
\text { Efficiency }\end{array}$ & $\begin{array}{l}\text { Model } 3 \text { Super } \\
\text { Efficiency - By } \\
\text { Shared Service } \\
\text { Type }\end{array}$ & $\begin{array}{l}\text { Model } 4 \\
\text { Bootstrapped } \\
\text { Efficiency }\end{array}$ \\
\hline Population $(\ln )$ & $\begin{array}{l}-0.1753^{*} \\
(0.0744)\end{array}$ & $\begin{array}{l}-0.7545^{* *} \\
(0.1533)\end{array}$ & $\begin{array}{l}-0.8326^{* *} \\
(0.1611)\end{array}$ & $\begin{array}{l}-0.2738 * * \\
(0.0855)\end{array}$ \\
\hline $\begin{array}{l}\text { Population } \\
\text { squared (ln) }\end{array}$ & & $\begin{array}{l}0.0336 * * \\
(0.0078)\end{array}$ & $\begin{array}{l}0.0410 * * \\
(0.0087)\end{array}$ & $\begin{array}{l}0.0163 * * \\
(0.0046)\end{array}$ \\
\hline Population & $0.0574 * *$ & $0.0444 * *$ & $0.0498 * *$ & $0.0377 * *$ \\
\hline Density (ln) & $(0.0165)$ & $(0.0164)$ & $(0.0170)$ & $(0.0090)$ \\
\hline Under 15 & $\begin{array}{l}0.0246 * * \\
(0.0054)\end{array}$ & $\begin{array}{l}0.0260 * * \\
(0.0053)\end{array}$ & $\begin{array}{l}0.0225^{* *} \\
(0.0058)\end{array}$ & $\begin{array}{l}0.0108 * * \\
(0.0031)\end{array}$ \\
\hline Aged (ln) & $\begin{array}{l}0.2756 * * \\
(0.0483)\end{array}$ & $\begin{array}{l}0.2364 * * \\
(0.0479)\end{array}$ & $\begin{array}{l}0.1795 * * \\
(0.0512)\end{array}$ & $\begin{array}{l}0.1539 * * \\
(0.0272)\end{array}$ \\
\hline Newstart (ln) & $\begin{array}{l}-0.1787 * * \\
(0.0551)\end{array}$ & $\begin{array}{l}-0.1113^{*} \\
(0.0559)\end{array}$ & $\begin{array}{l}-0.0969+ \\
(0.0582)\end{array}$ & $\begin{array}{l}-0.1282^{* *} \\
(0.0309)\end{array}$ \\
\hline NESB (ln) & $\begin{array}{l}0.0428+ \\
(0.0224)\end{array}$ & $\begin{array}{l}0.0401+ \\
(0.0219)\end{array}$ & $\begin{array}{l}0.0068 \\
(0.0243)\end{array}$ & $\begin{array}{l}-0.0179 \\
(0.0129)\end{array}$ \\
\hline ATSI (ln) & $\begin{array}{l}-0.0671^{*} \\
(0.0264)\end{array}$ & $\begin{array}{l}-0.0728 * * \\
(0.0257)\end{array}$ & $\begin{array}{l}-0.0606 * \\
(0.0259)\end{array}$ & $\begin{array}{l}-0.0309 * \\
(0.0137)\end{array}$ \\
\hline $\begin{array}{l}\text { Median Wage } \\
(\$ ' 000)\end{array}$ & $\begin{array}{l}-0.0077 * \\
(0.0029)\end{array}$ & $\begin{array}{l}-0.0064 * \\
(0.0028)\end{array}$ & $\begin{array}{l}-0.0065^{*} \\
(0.0028)\end{array}$ & $\begin{array}{l}-0.0058 * * \\
(0.0015)\end{array}$ \\
\hline $\begin{array}{l}\text { Financial } \\
\text { Assistance Grant }\end{array}$ & $\begin{array}{l}0.00002 \\
(0.00001)\end{array}$ & $\begin{array}{l}0.0000 \\
(0.0000)\end{array}$ & $\begin{array}{l}0.0000 \\
(0.0000)\end{array}$ & $\begin{array}{l}0.0000 \\
(0.0000)\end{array}$ \\
\hline Shared Services & $\begin{array}{l}-0.0677 * \\
(0.0331)\end{array}$ & $\begin{array}{l}-0.0847 * * \\
(0.0324)\end{array}$ & & \\
\hline Shared Waste & & & $\begin{array}{l}-0.0816 * \\
(0.0426)\end{array}$ & $\begin{array}{l}-0.0531 * \\
(0.0226)\end{array}$ \\
\hline Shared Water & & & -0.0726 & -0.0427 \\
\hline
\end{tabular}




\begin{tabular}{|c|c|c|c|c|}
\hline & & & $(0.0674)$ & $(0.0357)$ \\
\hline Shared Health & & & 0.1031 & 0.0390 \\
\hline & & & $(0.0711)$ & $(0.0377)$ \\
\hline Shared Flood & & & $-0.0925^{*}$ & $-0.0758 * *$ \\
\hline & & & $(0.0470)$ & $(0.0249)$ \\
\hline Shared Transp & & & 0.0493 & -0.0263 \\
\hline & & & $(0.0606)$ & $(0.0321)$ \\
\hline Shared Cemete & & & -0.0863 & -0.0264 \\
\hline & & & $(0.0827)$ & $(0.0438)$ \\
\hline Shared Equipn & & & 0.0738 & 0.0135 \\
\hline & & & $(0.0539)$ & $(0.0286)$ \\
\hline Shared & & & $-0.1197+$ & $-0.0825^{*}$ \\
\hline Procurement & & & $(0.0662)$ & $(0.0351)$ \\
\hline Rural & $0.1584 * *$ & $0.1858 * *$ & $0.1942 * *$ & $0.2430 * *$ \\
\hline & $(0.0547)$ & $(0.0537)$ & $(0.0553)$ & $(0.0293)$ \\
\hline $\mathrm{n}$ & 340 & 340 & 340 & 340 \\
\hline Coefficient of & 1.962 & 2.206 & 2.362 & 1.453 \\
\hline Determination & & & & \\
\hline (pseudo) & & & & \\
\hline
\end{tabular}

$+\mathrm{p}<0.10, * \mathrm{p}<0.05, * * \mathrm{p}<0.01$.

Standard errors in parentheses.

Table 4. Expected Characteristics of Statistically Significant Shared Services.

\begin{tabular}{|c|c|c|c|c|}
\hline Service Type & $\begin{array}{l}\text { Significant } \\
\text { Association }\end{array}$ & Measurability & Specificity & $\begin{array}{l}\text { Homogeneity of } \\
\text { Preferences }\end{array}$ \\
\hline Waste & -0.0816 & High & $\begin{array}{l}\text { High (rubbish trucks } \\
\text { and refuse tips are } \\
\text { very specific assets) }\end{array}$ & $\begin{array}{l}\text { Medium } \\
\text { (different types } \\
\text { of recycling } \\
\text { occur in } \\
\text { different } \\
\text { municipalities) }\end{array}$ \\
\hline $\begin{array}{l}\text { Flood } \\
\text { Mitigation }\end{array}$ & -0.0925 & $\begin{array}{l}\text { Low (flood } \\
\text { events are } \\
\text { unpredictable) }\end{array}$ & $\begin{array}{l}\text { High (assets such as } \\
\text { levy banks cannot be } \\
\text { redeployed) }\end{array}$ & $\begin{array}{l}\text { High (tolerance } \\
\text { for flooding } \\
\text { would generally } \\
\text { be low) }\end{array}$ \\
\hline Procurement & -0.1197 & Medium & Low (few assets & Relatively high \\
\hline
\end{tabular}




$\begin{array}{ll}\text { (comparison } & \text { employed and staff } \\ \text { against } & \text { would be re- } \\ \text { historical cost } & \text { deployable) } \\ \text { data loses } & \\ \text { relevance over } & \\ \text { time) } & \end{array}$

